\title{
Comparative Study on Microwave Co-pyrolysis Products of Low-Rank Coal under $\mathrm{CH}_{4}$ and $\mathrm{N}_{2}$ Atmosphere
}

\author{
Jun Zhou ${ }^{1,2, a}$, Zhe Yang ${ }^{1}$, Lei Wu ${ }^{3}$, Qiuli Zhang ${ }^{1,2}$, Xiangyang Chen ${ }^{1,2}$, Xicheng Zhao ${ }^{1,2}$ \\ 1School of Metallurgical Engineering, Xi' an University of Architecture and Technology, Xi'an 710055, \\ Shaanxi, P.R. China \\ 2Shaanxi Province Metallurgical Engineering and Technology Research Centre, Xi'an 710055, \\ Shaanxi, P.R. China
}

3Xinjiang Chemical Engineering Design \& Research Institute Co., Ltd., Urumqi 830006, Xinjiang, P.R. China

axazhoujun@126.com

\begin{abstract}
Keywords: Low-rank coal; Microwave co-pyrolysis; Products; Methane; Nitrogen.
Abstract. Microwave pyrolysis is a new research method for deeply processing of low-rank coal. This paper conducted comparative study on microwave co-pyrolysis products of low-rank coal under $\mathrm{CH}_{4}$ and $\mathrm{N}_{2}$ atmosphere, respectively. The composition and content of tar and bluecoke were analyzed by gas chromatography-mass spectrometry and fourier transform infrared spectrometer. The results indicated that compared with $\mathrm{N}_{2}$ atmosphere, the yield of liquid products (tar and pyrolysis water) obtained under $\mathrm{CH}_{4}$ atmosphere increased by $5.4 \mathrm{wt} . \%$, whereas the bluecoke yield decreased by 3.0 wt.\%; The content of $\mathrm{S}$ element in the bluecoke obtained under $\mathrm{CH}_{4}$ atmosphere was less than 0.30 wt.\% to meet Bluecoke Standard S-1 Grade, and the ash content was just 6.72 wt.\% to meet Bluecoke Standard A-3 Grade. Furthermore, the content of $-\mathrm{OH} 、 \mathrm{C}=\mathrm{C}$ and $-\mathrm{C}=\mathrm{O}$ functional groups in the bluecoke were higher; The alkanes and olefins compound content in tar obtained under $\mathrm{CH}_{4}$ atmosphere were $9.1 \mathrm{wt} . \%$ and $7.9 \mathrm{wt} . \%$ higher than that under $\mathrm{N}_{2}$ atmosphere, meanwhile, the aromatic hydrocarbons compound content was $35.5 \mathrm{wt} . \%$ lower than that under $\mathrm{N}_{2}$ atmosphere.
\end{abstract}

\section{Introduction}

The thermal treatment technology of coal has been developing for thousands of years, and it was still the most important technology that makes full use of coal resources in the current background of energy crisis[1]. Coal pyrolysis and other thermal treatment technologies (e.g., gasification, liquefaction, combustion and carbonization, etc.) have a very close relationship. The modification and upgrading of coal by pyrolysising at low temperature are of great practical importance because it creates new opportunities for enlarging coal resources usable for coking. China is rich in low-rank coal resources, accounting for more than $45 \%$ of the total proven reserves of coal resources [2]. The medium-low temperature pyrolysis of low-rank coal to realize separation and transformation of its gas, liquid and solid components, thus making for further upgrading utilization of three-phase products, is considered to be the best way to increase the value-added of its products [3]. Numerous scholars through lots of experimental studies have found reaction atmosphere had much significantly influence on the composition and distribution of pyrolysis products. Takarada et al. [4] performed catalytic pyrolysis experiment of coal in powder fluidized bed and found that the benzene-toluene-xylene (BTX) content obtained from catalytic pyrolysis unedr $\mathrm{H}_{2}$ atmosphere was 3 to 4 times higher than $\mathrm{N}_{2}$ atmosphere. McCown et al. [5] studied that Louisiana lignite pyrolysis at $800^{\circ} \mathrm{C}$ under $\mathrm{H}_{2}$ and $\mathrm{N}_{2}$ atmosphere respectively, the results indicated that the yield of volatile obtained under $\mathrm{H}_{2}$ atmosphere was about $14.5 \%$ higher than that under $\mathrm{N}_{2}$ atmosphere. In recent years, microwave pyrolysis technology of coal, which has its unique law of heat and mass transfer, good heating uniformity, easily controlled temperature and pyrolysis process, higher target product yield, and more valuable $\mathrm{H}_{2}, \mathrm{CH}_{4}$, and $\mathrm{CO}$ content of coal gas, gradually developed as a new type of clean coal carbonization technology [6]. Therefore, working on the coal-gas microwave co-pyrolysis [7] 
experimental research is a beneficial attempt to realize clean conversion utilization of coal, which has important practical significance. This paper conducted comparative study on microwave co-pyrolysis products of low-rank coal under $\mathrm{CH}_{4}$ and $\mathrm{N}_{2}$ atmosphere in the optimal pyrolysis process conditions.

\section{Experimental}

Coal samples. Low-rank coal was used for the experimental material, it was cruched and sized to a range from 5 to $10 \mathrm{~mm}$, followed by dewatering at $100^{\circ} \mathrm{C}$ for $12 \mathrm{~h}$ in a vacuum oven before being used for pyrolysis experiments. The proximate and ultimate analyses of coal samples are showed in Table 1.

Table 1 Proximate and ultimate analyses of coal samples (wt.\%, ad)

\begin{tabular}{|c|c|c|c|c|c|c|c|c|}
\hline \multicolumn{4}{|c|}{ Proximate analysis } & \multicolumn{5}{|c|}{ Ultimate analysis } \\
\hline $\mathrm{M}$ & A & $\mathrm{FC}$ & $\mathrm{V}$ & $\mathrm{C}$ & $\mathrm{H}$ & $\mathrm{N}$ & $\mathrm{S}_{\mathrm{t}}$ & $\mathrm{O}$ \\
\hline 3.41 & 2.64 & 56.16 & 37.79 & 76.38 & 4.71 & 0.99 & 0.26 & 11.61 \\
\hline
\end{tabular}

Experimental apparatus and methods. Experimental apparatus of low-rank coal microwave co-pyrolysis under $\mathrm{CH}_{4}$ and $\mathrm{N}_{2}$ atmosphere are shown in Fig.1. It was mainly made up of the carrier gas system, microwave equipment, product cooling system, gas collecting system and temperature recording system. A certain amount of coal samples were fed into a custom-designed quartz tube reactor with the size of $55 \mathrm{~mm}$ in diameter and $600 \mathrm{~mm}$ in length. $\mathrm{CH}_{4}$ and $\mathrm{N}_{2}$ were provided by gas cylinder, the pressure reduction valve and rotor flow meter could provide a relatively stable pressure environment. Weight difference method was adopted to calculate the solid and liquid products (tar and pyrolysis water) yield and weight loss rate of coal samples after the end of pyrolysis reaction. Related formulas were defined as Formula (1-3).

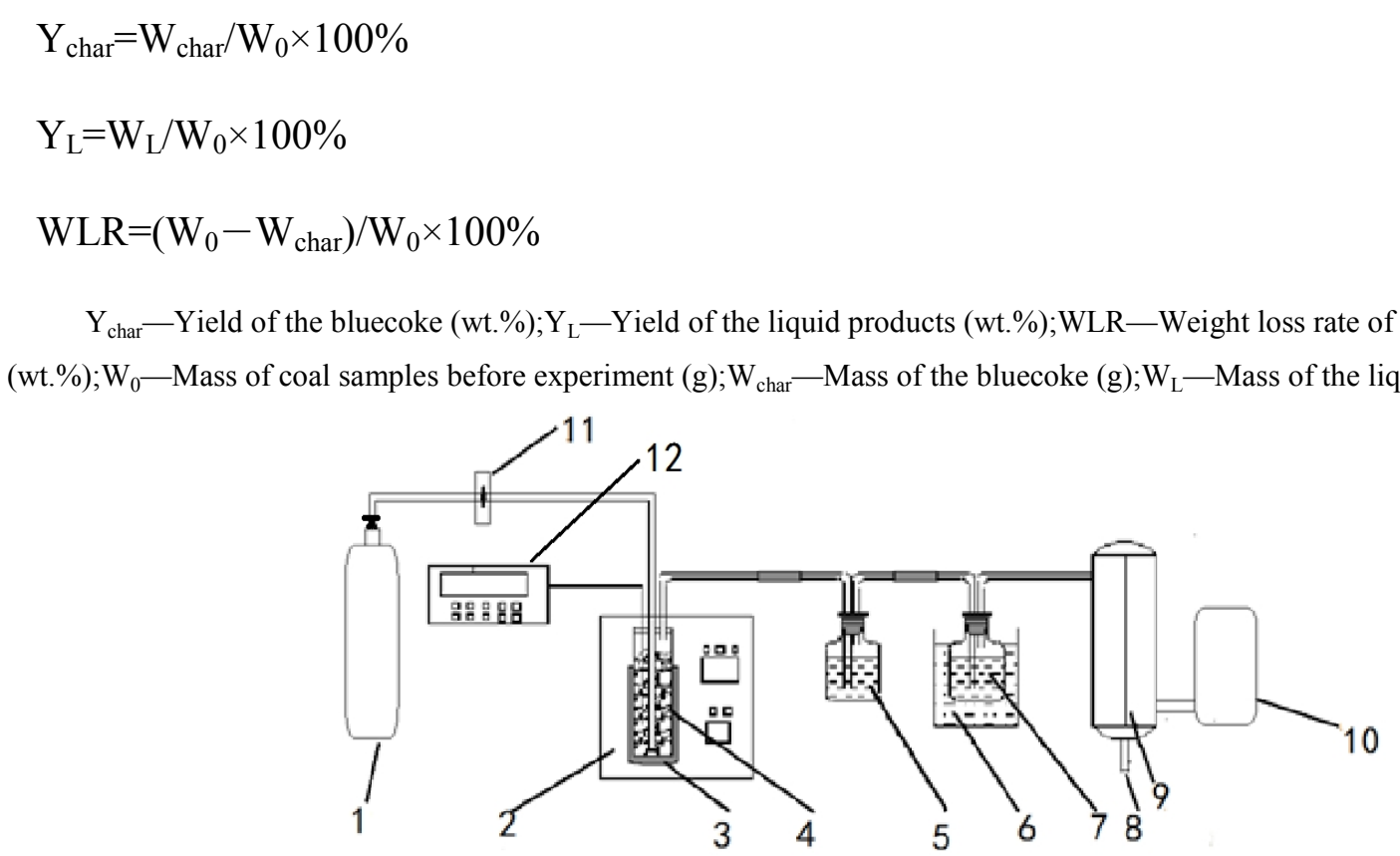

Figure1. Experimental apparatus of low-rank coal microwave co-pyrolysis under $\mathrm{CH}_{4}$ and $\mathrm{N}_{2}$ atmosphere 1-Gas cylinder; 2-Microwave device; 3-Asbestos cover; 4-Quartz reactor; 5-Water bottle; 6-Ice bath; 7-Water bottle; 8-Tar collecting; 9-Tar trap; 10- Gas pocket; 11-Rotameter; 12 - Temperature display

\section{Results and discussion}

Yield of pyrolysis products. The yield of pyrolysis products and weight loss rate of coal samples obtained under $\mathrm{CH}_{4}$ and $\mathrm{N}_{2}$ atmosphere are showed in Table 2. It could be easily found that the yield 
of liquid products and bluecoke obtained under $\mathrm{CH}_{4}$ atmosphere were up to $23.4 \mathrm{wt} . \%$ and $62.8 \mathrm{wt} . \%$, respectively. Compared with $\mathrm{N}_{2}$ atmosphere, the liquid products yield increased by 5.4 wt.\%, whereas the bluecoke yield decreased by 3.0 wt.\%. It suggests that $\mathrm{CH}_{4}$ could contribute to the formation of liquid products during the coal pyrolysis.

Table 2 Yield of pyrolysis products and WLR of coal samples under $\mathrm{CH}_{4}$ and $\mathrm{N}_{2}$ atmosphere(wt.\%)

\begin{tabular}{ccc}
\hline Item & $\mathrm{CH}_{4}$ & $\mathrm{~N}_{2}$ \\
\hline $\mathrm{Y}_{\text {char }}$ & 62.8 & 65.8 \\
$\mathrm{Y}_{\mathrm{L}}$ & 23.4 & 18.0 \\
WLR & 37.2 & 34.2 \\
\hline
\end{tabular}

Analysis of the bluecoke. The proximate and ultimate analyses of the bluecoke obtained under $\mathrm{CH}_{4}$ and $\mathrm{N}_{2}$ atmosphere are showed in Table 3. According to the analyses of raw coal quality (Table 1), Table 3 shows that the volatile and $\mathrm{H}$ element content in the bluecoke obtained under $\mathrm{CH}_{4}$ and $\mathrm{N}_{2}$ atmosphere decreased obviously, while the ash, fixed carbon and $\mathrm{C}$ element content increased significantly. Therefore, coal pyrolysis is essentially a process of dehydrogenation, deoxygenation, and carbon enrichment. According to China Bluecoke Standard Classification and quality grading for bluecoke[8], compared with $\mathrm{N}_{2}$ atmosphere, the content of S element in the bluecoke obtained under $\mathrm{CH}_{4}$ atmosphere was less than 0.30 wt.\% to meet Bluecoke Standard S-1 Grade, and the ash content was just 6.72 wt.\% to meet Bluecoke Standard A-3 Grade. It suggests that $\mathrm{CH}_{4}$ promotes more completely pyrolysis of low-rank coal. Fig. 2 shows FTIR spectra of the bluecoke obtained under $\mathrm{CH}_{4}$ and $\mathrm{N}_{2}$ atmosphere. It can be seen that peak position of the bluecoke in FTIR spectra are basically the same, but larger differences exists in distinctive peak area. It indicates that pyrolysis atmosphere had stronger influence on the content of distinctive functional groups in bluecoke. Compared to the standard FTIR spectra library, the peak at $3450 \mathrm{~cm}^{-1}$ was ascribed to the stretching vibration of $-\mathrm{OH}$ or $-\mathrm{NH}$ functional groups associated by hydrogen bond, $-\mathrm{NH}$ functional groups had little influence due to lower content of $\mathrm{N}$ element in low rank coal, so - $\mathrm{OH}$ functional groups content may be higher due to more strongly peak position transformation. The peaks at $1600 \mathrm{~cm}^{-1}$ was attributed to the stretching vibration of aromatic ring $\mathrm{C}=\mathrm{C}$ double bond and $-\mathrm{C}=\mathrm{O}$ associated by hydrogen bond. It can be easily found that the content of $-\mathrm{OH} 、 \mathrm{C}=\mathrm{C}$ and $-\mathrm{C}=\mathrm{O}$ functional groups in the bluecoke obtained under $\mathrm{CH}_{4}$ atmosphere were higher than that under $\mathrm{N}_{2}$ atmosphere.

Table 3 Proximate and ultimate analyses of the bluecoke obtained under $\mathrm{CH}_{4}$ and $\mathrm{N}_{2}$ atmosphere (wt.\%, ad)

\begin{tabular}{|c|c|c|c|c|c|c|c|c|}
\hline \multirow{2}{*}{ Atmosphere } & \multicolumn{4}{|c|}{ Proximate analysis } & \multicolumn{4}{|c|}{ Ultimate analysis } \\
\hline & M & A & $\mathrm{FC}$ & $\mathrm{V}$ & $\mathrm{C}$ & $\mathrm{H}$ & $\mathrm{N}$ & $\mathrm{S}_{\mathrm{t}}$ \\
\hline $\mathrm{CH}_{4}$ & 0.25 & 6.72 & 84.7 & 3.92 & 87.0 & 0.89 & 0.88 & 0.29 \\
\hline $\mathrm{N}_{2}$ & 1.10 & 7.28 & 86.9 & 4.71 & 86.4 & 1.16 & 1.02 & 0.32 \\
\hline
\end{tabular}

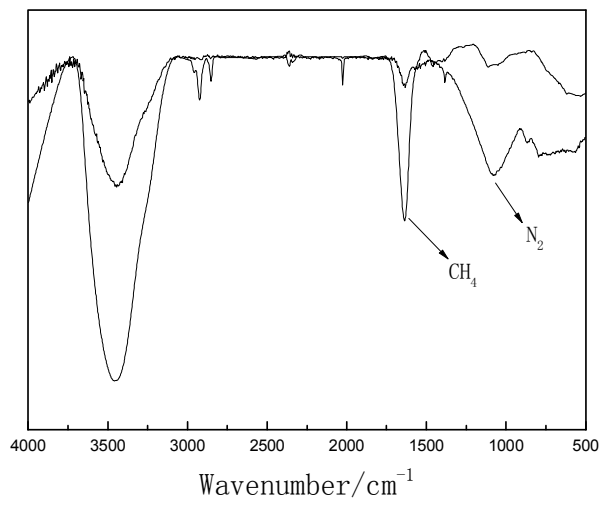

Figure2. FTIR spectra of the bluecoke obtained under $\mathrm{CH}_{4}$ and $\mathrm{N}_{2}$ atmosphere 
Analysis of the tar. The tar was analyzed by gas chromatography-mass spectrometry (GC-MS) after separating water from liquid products. Main components content of the tar obtained under $\mathrm{CH}_{4}$ and $\mathrm{N}_{2}$ atmosphere are given in Table 4. It can be seen in table 4 that the alkanes and olefins compound content in tar obtained under $\mathrm{CH}_{4}$ atmosphere were up to $41.3 \mathrm{wt} . \%$ and $15.4 \mathrm{wt} . \%$, respectively. Whereas the aromatic hydrocarbons compound content was just $8.70 \mathrm{wt} . \%$. The alkanes and olefins compound content in tar obtained under $\mathrm{CH}_{4}$ atmosphere were $9.1 \mathrm{wt} . \%$ and $7.9 \mathrm{wt} . \%$ higher than that under $\mathrm{N}_{2}$ atmosphere, meanwhile, the aromatic hydrocarbons compound content was $35.5 \mathrm{wt} \%$ lower than that under $\mathrm{N}_{2}$ atmosphere. It suggests that $\mathrm{CH}_{4}$ is more conducive to the formation of light component in coal tar during the coal pyrolysis.

Table 4 Main components content of the tar obtained under $\mathrm{CH}_{4}$ and $\mathrm{N}_{2}$ atmosphere (wt.\%)

\begin{tabular}{ccccc}
\hline Atmosphere & Alkanes & Olefins & Aromatic hydrocarbons & Oxygen-containing functional groups \\
\hline $\mathrm{CH}_{4}$ & 41.3 & 15.4 & 8.70 & 23.9 \\
$\mathrm{~N}_{2}$ & 32.2 & 7.50 & 44.2 & 8.90 \\
\hline
\end{tabular}

\section{Conclusions}

(1) Compared with $\mathrm{N}_{2}$ atmosphere, the yield of liquid products (tar and pyrolysis water) obtained under $\mathrm{CH}_{4}$ atmosphere increased by $5.4 \mathrm{wt} . \%$, whereas the bluecoke yield decreased by $3.0 \mathrm{wt} . \%$.

(2) Compared with $\mathrm{N}_{2}$ atmosphere, the content of S element in the bluecoke obtained under $\mathrm{CH}_{4}$ atmosphere was less than $0.30 \mathrm{wt} . \%$ to meet Bluecoke Standard S-1 Grade, and the ash content was just 6.72 wt.\% to meet Bluecoke Standard A-3 Grade. Furthermore, the content of $-\mathrm{OH} 、 \mathrm{C}=\mathrm{C}$ and $-\mathrm{C}$ $=\mathrm{O}$ functional groups in the bluecoke were higher.

(3) The alkanes and olefins compound content in tar obtained under $\mathrm{CH}_{4}$ atmosphere were 9.1 wt.\% and 7.9 wt.\% higher than that under $\mathrm{N}_{2}$ atmosphere, meanwhile, the aromatic hydrocarbons compounds content was 35.5 wt.\% lower than that under $\mathrm{N}_{2}$ atmosphere.

\section{Acknowledgments}

This project was financially supported by the Shaanxi Provincial Balanced-planning Science and Innovation Engineering Program of China (no. 2011KTDZ01-05-04), the Scientific Research Program of Shaanxi Provincial Education Department (no. 12JK0583), and the Yulin Planning Project of Science and Technology.

\section{References}

[1]Yanxing Ma, Zhichao Ma. Chinese Annual Conference on Chemical and Biochemical Engineering, 2010.

[2] BP Statistical Review of World Energy 2011, BP Company, 2011.

[3] Shang Jianxuan, Wang Lijie, Gan Jianping. Coal Conversion. Vol.34, No.1(2011), pp.92-96.

[4]Takayuki Takarada, Yoshiyuki Onoyama, Kenji Takayama, et al.: Catalysis Today. Vol.39, No.(1-2) (1997), pp.127-136.

[5] McCown M S, Harrison D P. Fuel. Vol.61, No.11(1982), pp.1149-1156.

[6] Lan Xinzhe, Zhao Xicheng, Ma Hongzhou, et al.: China Patent, ZL200810232680.4, 2009.

[7] Zhou Jun, Lan Xinzhe, Zhao Xicheng, et al.: China Patent, ZL201220436061.9, 2013.

[8] Luo Yunfei, Li Jinzhu, Lan Xinzhe, et al.: China Standard, GB/T 25212-2010, 2010. 